\title{
Pollen Development and Chilling Requirements in Apricot Cultivars
}

\author{
C. Julian $^{1}$, M. Herrero ${ }^{2}$ and J.Rodrigo ${ }^{1}$ \\ ${ }^{1}$ Centro de Investigación de Tecnología Agroalimentaria (CITA-DGA). Avda Montañana \\ 930, 50059 Zaragoza. \\ ${ }^{2}$ Estación Experimental Aula Dei, CSIC. Apartado 202, 50080 Zaragoza. \\ email: cjulianla@aragon.es
}

Keywords: anthers, bud burst, dormancy, flower bud, meiosis, Prunus armeniaca

\begin{abstract}
Apricot (Prunus armeniaca L.) flowers at the end of the winter but flower bud differentiation occurs the previous summer. During the winter, the flower bud enters dormancy and resumes growth prior to flowering. The time the flower bud remains dormant is genetically and also environmentally controlled and is a major factor determining the adaptation of particular cultivars to particular ecological conditions. In apricot, as in other temperate fruit species, chilling is required for buds to emerge from rest and chilling requirements vary greatly among cultivars. However, very little is known on the physiological changes underlying these events. To explore the relationship between pollen development and chilling requirements, anther and pollen development have been characterised in several apricot cultivars with different chilling requirements. For this purpose, sequentially fixed flower buds from dormancy to flowering were histochemically examined in two consecutive years. While the pattern of pollen development is highly conserved, differences in timing were observed among the different cultivars and years. These differences are discussed in relation to the chilling requirements for each cultivar.
\end{abstract}

\section{INTRODUCTION}

In most temperate fruit trees, flower buds differentiate the previous summer, enter dormancy during the winter and resume growth prior to flower the next spring. The time the flower bud remains dormant is genetically and also environmentally controlled and is a major factor determining the adaptation of species and cultivars to particular ecological conditions (Faust et al., 1997).

In apricot, as in other temperate fruit species, chilling is required for buds to emerge from rest, although the mechanisms underpinning chilling are largely unknown. Thus, while chilling requirements vary greatly among cultivars (Layne et al., 1996), little is known on the physiological changes underlying these differences. Likewise, it is difficult to establish when flower buds have broken endodormancy and resume growth since no signs of development can be detected until budbreak several weeks later.

In this work, in order to explore the relationship between pollen development and chilling requirements, anther and pollen development have been characterised in several apricot cultivars with different chilling requirements.

\section{MATERIALS AND METHODS}

Trees of several apricot cultivars (Currot, Moniqui and Paviot in 2006, and Canino, Corbato, Currot, Moniqui, Paviot and Luizet in 2007) were selected from an experimental orchard located at CITA in Zaragoza, Spain. To examine the internal 
development, ten flower buds were weekly sampled over eight weeks between December and February and, after the removal of bud scales, fixed in FAA. Anthers of five fixed flower buds were removed by a scalpel and stained with aniline blue (Currier, 1957) or DAPI (Williams et al., 1999), squashed and observed under a fluorescence microscope. Daily records of temperature were registered in a meteorological station located in the research centre. Chilling fulfilment of each cultivar was estimated as the number of hours below $7.2^{\circ} \mathrm{C}$ from November (Weinberger, 1950) according to previous determination of chilling requirements for the same apricot cultivars in the same area (Tabuenca, 1968; Table 1).

\section{RESULTS AND DISCUSSION}

During endordormancy, the pollen mother cell (PMC) stage, prior to meiosis, was observed in all cultivars (Table 1). The transition from PMC to meiosis took place once chilling requirements were fulfilled. The meiosis process occurred while flower buds were still closed in stage A (Baggiolini, 1952), and the meiocytes reached the tetrad stage within one week. While the beginning of meiosis has been related to chilling accumulation with independence of the chilling requirements of cultivars (Bartolini et al., 2006), results herein showed a relationship between the end of endodormancy and the onset of meiosis, since, in general, those cultivars with low chilling requirements underwent meiosis earlier than those with high requirements.

The process of pollen development from endodormancy to bud burst was highly conserved in all cultivars and years. However, differences in timing were observed between the cultivars analysed in mild winter conditions according to their chilling requirements. Thus, those apricot cultivars that underwent first male meiosis flowered earlier than those that reached meiosis later (Table 2). The time elapsed from meiosis to flowering ranged between 4-6 weeks. While in a cold winter (2006) slight differences in pollen and flower bud development were observed between cultivars, under mild winter conditions (2007) differences in both processes were higher.

While meiosis cannot be considered as a precise parameter to calculate chilling hours, the correspondence between chilling fulfillment, the onset of meiosis and the flowering time in the cultivars studied show that pollen meiosis is not only environmentally but also genetically regulated and indicate that chilling requirements have been fulfilled.

\section{ACKNOWLEDGEMENTS}

Financial support was provided by FEDER-CICYT (AGL2003-05318-C02-00 and AGL-2006-13529-CO2-00/AGR) and by Grupo Consolidado de Aragón A-43 (DGA). C. J. was supported by a fellowship of INIA.

\section{Literature Cited}

Baggiolini, M. 1952. Les stades repérés des arbres fruitiers à noyau. Rev. Romande Agr. Et vit. $8: 1-8$.

Bartolini, S., Viti, R. and Guerriero, R. 2006. Xylem differentiation and microsporogenesis during dormancy of apricot flower buds (Prunus armeniaca L.). Eur. J. Hort. Sci. 71: 84-90.

Currier, H.B. 1957. Callose substance in plant cells. Am. J. Bot. 44: 478-488. 
Faust, M., Erez, A., Rowland, L.J., Wang, S.Y. and Norman, H.A. 1997. Bud dormancy in perennial fruit trees: Physiological basis for dormancy induction, maintenance, and release. Hortscience 32: 623-629.

Layne, R.E.C., Bailey, C.H. and Hough, L.F. 1996. pp 79-109. Apricots. In: J. Janick, and J. N. Moore (Eds): Fruit breeding. Vol. I: Tree and Tropical Fruits.

Tabuenca, M.C. 1968. Necesidades de frío invernal en variedades de albaricoquero. An. Aula. Dei, 9: 10-24.

Weinberger, J.H. 1950. Chilling requirements of peach varieties. Proc. Amer. Soc. Hort. Sci. 56, 122-128.

Williams, J.H., Friedman, W.E. and Arnold, M.L. 1999. Developmental selection within the angiosperm style: Using gamete DNA to visualize interspecific pollen competition. Proc. Natl. Acad. Sci. U. S. A. 96: 9201-9206.

\section{Tables}

Table 1. Pollen development according to chilling requirements fulfilled in 2007

\begin{tabular}{|c|c|c|c|c|c|c|c|}
\hline \multirow{3}{*}{$\begin{array}{c}\text { APRICOT } \\
\text { cvs }\end{array}$} & \multicolumn{6}{|c|}{ Chilling hours at sampling time } & \multirow{3}{*}{$\begin{array}{c}\text { Chilling } \\
\text { Requirements* }\end{array}$} \\
\hline & $21 / 12$ & $16 / 01$ & $26 / 01$ & $01 / 02$ & $09 / 02$ & $16 / 02$ & \\
\hline & 428 & 900 & 1059 & 1195 & 1328 & 1389 & \\
\hline CANINO & PMC & M & YM & & & & 711-779 \\
\hline CURROT & PMC & PMC & PMC-M & $\mathrm{T}$ & $\mathrm{T}-\mathrm{YM}$ & & 354-507 \\
\hline CORBATO & PMC & PMC & & M-T & $\mathrm{T}-\mathrm{YM}$ & & $750-786$ \\
\hline MONIQUI & PMC & PMC & PMC & M-T & $\mathrm{T}-\mathrm{YM}$ & YM & 779-926 \\
\hline PAVIOT & PMC & PMC & PMC & PMC-M & $\mathrm{T}$ & & 995-1075 \\
\hline LUIZET & PMC & PMC & PMC & PMC & PMC-M-T & & 1058-1116 \\
\hline
\end{tabular}

PMC: Pollen mother cell. M: Onset of meiosis. T: Tetrad, YM: Young microspore

*: Chilling requirements data from Tabuenca (1968)

Table 2. Dates from flower bud burst to bloom in 2007

\begin{tabular}{lcccccccccc}
\hline $\begin{array}{c}\text { APRICOT } \\
\text { cvs }\end{array}$ & $22 / 12$ & $01 / 02$ & $09 / 02$ & $12 / 02$ & $14 / 02$ & $16 / 02$ & $22 / 02$ & $26 / 02$ & $02 / 03$ & $04 / 03$ \\
\hline CANINO & $\mathrm{A}$ & $\mathrm{B}$ & $\mathrm{C} 1$ & $\mathrm{C} 1$ & $\mathrm{C} 2$ & $\mathrm{C} 3$ & $\mathrm{D} 1$ & $\mathrm{D} 3$ & $\mathrm{~F}$ & \\
\hline CURROT & $\mathrm{A}$ & $\mathrm{A}$ & $\mathrm{B}$ & $\mathrm{B}$ & $\mathrm{C} 1$ & $\mathrm{C} 1$ & $\mathrm{C} 3$ & $\mathrm{D} 1$ & $\mathrm{~F}$ & \\
\hline CORBATO & $\mathrm{A}$ & $\mathrm{A}$ & $\mathrm{B}$ & $\mathrm{B}$ & $\mathrm{B}$ & $\mathrm{C} 1$ & $\mathrm{C} 2$ & $\mathrm{C} 3$ & $\mathrm{E}$ & $\mathrm{F}$ \\
\hline MONIQUI & $\mathrm{A}$ & $\mathrm{A}$ & $\mathrm{B}$ & $\mathrm{B}$ & $\mathrm{B}$ & $\mathrm{C} 1$ & $\mathrm{C} 2$ & $\mathrm{C} 3$ & $\mathrm{~F}$ & \\
\hline PAVIOT & $\mathrm{A}$ & $\mathrm{A}$ & $\mathrm{A}$ & $\mathrm{B}$ & $\mathrm{B}$ & $\mathrm{C} 1$ & $\mathrm{C} 2$ & $\mathrm{C} 3$ & $\mathrm{D} 3$ & $\mathrm{~F}$ \\
\hline LUIZET & $\mathrm{A}$ & $\mathrm{A}$ & $\mathrm{A}$ & $\mathrm{B}$ & $\mathrm{B}$ & $\mathrm{C} 1$ & $\mathrm{C} 1$ & $\mathrm{C} 2$ & $\mathrm{D} 2$ & $\mathrm{~F}$ \\
\hline
\end{tabular}

